\title{
NEW GENERATION STABILITY NORMS -HOW TO APPROACH THE TASK
}

\author{
Lech Kobyliński \\ Polish Academy of Sciences \\ Foundation for Safety of Navigation and Environment Protection, Poland
}

\begin{abstract}
International stability norms included in the Code of Intact Stability 2008 adopted by IMO on 4 December 2008 constitutes the latest set of international requirements on intact stability of ships. However the requirements included in the Code, part of them compulsory (Included in the Part A of the Code), other only recommended (included in the Part B of the Code) are considered as not totally sufficient to assure safety of ships. Because of that, IMO decided that there would be the necessity to develop so called new generation stability criteria covering certain identified hazards, such as parametric resonance, loss of stability in the wave crest broaching, dead ship condition and excessive accelerations when rolling. Those criteria, or rather stability norms, are under development since 2008. The present approach, the work on which is well advanced, is however, not fully satisfactory and several important problems were discovered. This approach may need to be reconsidered or supplemented. The author in the paper presented discusses the weak points of the current approach and proposes possible different approach in order to make future ships safer from the stability point of view.
\end{abstract}

Keywords: ship stability, stability standards, risk assessment

\section{CURRENT INTERNATIONAL STABILITY REQUIREMENTS AND THEIR DEVELOPMENT}

The current stability standards are included in the International Code on Intact Stability 2008, adopted by the expanded Marine Safety Committee of the International Maritime Organisation (IMO) on 4 December 2008 [1]

The short history of the Code is as follows. The first internationally accepted stability criteria were statistical criteria developed by the STAB Sub-committee of IMCO (IMO) in the years 1962-67 and adopted as recommended in 1968 by IMCO Assembly resolutions A.167(AS.IV) and A.168(ES.IV). Those standards were developed by delegations of Poland and Federal Republic of Germany. They were based on statistical data.

During the period 1978-82 STAB Sub-committee developed so called "Weather Criterion" for passenger and cargo vessels, adopted ultimately in 1985 by IMO Assembly Resolution A.562(14) and later on, for fishing vessels in 1991 by Resolution A.685(17). Weather criterion was based on the approach adopted in national requirements of the USSR several years earlier. This approach consisted of consideration of action of severe wind and waves in dead ship condition. There were also adopted in the meantime several other resolutions related to various aspects of stability, amongst them resolutions related to stability of vessels of different 
types. All requirements included in these resolutions were recommended only, none of them was considered compulsory.

The standards developed were criticised from the very beginning after they were adopted. During the discussions at STAB Sub-Committee and also in other places it was stressed that in development of those standards several assumptions were made making them non-rigorous. However the practical application of the above stability standards revealed, that for the great majority of ships they worked well and the number of stability accidents was greatly reduced. Still, however, several delegations to IMO insisted on further development of more rigorous stability standards in order to increase safety of ships at sea. Several proposals were advanced in this context, none, however, gained wider support. Obviously the problem is to complex.

In order to make some progress IMO decided to make one comprehensive document that would include all resolutions and requirements already developed and split between several different documents. The idea of development of Intact Stability Code was advanced and finally, after lengthy discussion, the Code was developed. It was also agreed that this code should be based on system approach [2]. Finally Intact Stability Code was adopted in 1993 by IMO Assembly by resolution A.749(18). The Code was subsequently amended in 2002. Since then, however, discussion started again on the possibilities to improve level of safety against capsizing and to revise the criteria. It was agreed by the IMO that the most important motion would be to make stability criteria compulsory. This was achieved by drafting new edition of the Code, that was adopted ultimately in 2008. Both editions of the Code included stability criteria virtually unchanged from the original criteria recommended by the above mentioned resolutions.

The 2008 edition of the Code consists of three parts: Part A, Part B and Explanatory Notes.

Part A of the Code was made compulsory by proper reference in the SOLAS Convention. It includes basic criteria: statistical criteria and weather criterion for both passenger and cargo ships and fishing vessels. Only minor improvements from the previous editions were included.

Part B of the Code includes provisions for specific types of ships and other provisions that are recommended only. That makes possible to amend this part of the Code more often as deemed necessary and to include criteria and provisions that may be not sufficiently validated during a trial period.

\section{SECOND GENERATION STABILITY CRITERIA}

Having prepared the 2008 edition of the Intact Stability Code, the SLF Sub-Committee was, however, not satisfied with the stability criteria in force. The point was raised by some delegations, that several situations dangerous from the point of view of stability are not covered by the criteria. According to some delegations the following situations or stability failure modes should be considered:

- Parametric resonance in following and head seas

- Loss of stability in the wave crest

- $\quad$ Broaching to and surfing

- Dead ship condition, and

- Excessive accelerations when rolling

Actually the proposal was not new. Those situations were considered by the Sub-committee during late seventies and early eighties of the last century. At that time Polish delegation to IMO proposed to consider those situations [3], apart from the last one, but after brief discussion the Subcommittee decided that it was unable to work out usable recommendations in that respect. Several years later the Subcommittee agreed to consider those situations under the agenda item "Second generation stability criteria".

Tab. 1. Three levels vulnerability approach within second generation stability criteria

\begin{tabular}{|l|l|l|l|l|}
\hline LEVEL 1 & LEVEL 2 & $\begin{array}{l}\text { DIRECT } \\
\text { STABILITY } \\
\text { ASSESSMENT }\end{array}$ & $\begin{array}{l}\text { OPERATIONAL } \\
\text { GUIDANCE }\end{array}$ \\
\hline $\begin{array}{l}\text { stability } \\
\text { failure } \\
\text { mode }\end{array}$ & $\begin{array}{l}\text { simple and } \\
\text { conservative } \\
\text { criteria based } \\
\text { on geometry } \\
\text { of hull and } \\
\text { speed }\end{array}$ & $\begin{array}{l}\text { less } \\
\text { conservative } \\
\text { criteria, } \\
\text { based on } \\
\text { simplified } \\
\text { physics and } \\
\text { involving } \\
\text { simplified } \\
\text { computations }\end{array}$ & $\begin{array}{l}\text { numerical } \\
\text { simulation } \\
\text { of physical } \\
\text { phenomena } \\
\text { based on } \\
\text { computer } \\
\text { codes } \\
\text { developed }\end{array}$ & $\begin{array}{l}\text { based on } \\
\text { experience }\end{array}$ \\
\hline
\end{tabular}

Work on second generation stability criteria started in 2008 [4]. After rather lengthy discussion of the matter during several sessions, the Subcommittee agreed that with regard of those situations safety assessment based on the three-levels vulnerability check have to be applied. The idea of this approach is that during the design stage of the ship, vulnerability to those stability failures at three levels have to be checked [5]. as shown in the table 1. Fig.1 shows schematically process of checking vulnerability to all four stability failure modes.

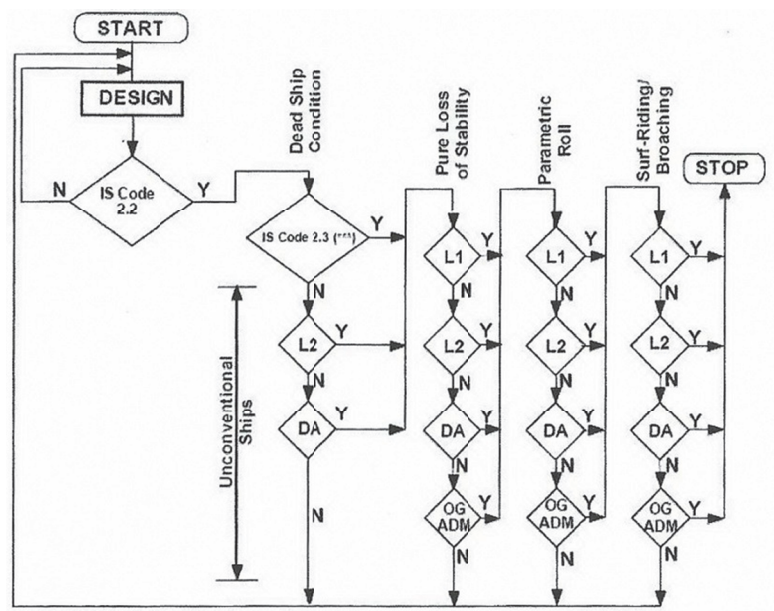

Fig.1. Schematic presentation of the process of checking vulnerability to four stability failure modes (from [6]) 
The SLF Subcommittee assumed that three to four years may be sufficient to complete the criteria, however, when the work started the Subcommittee realized that this is not an easy task. After eight years of discussion and extensive work on the criteria, the present situation is as follows: draft of the level 1 and 2 criteria has been finalized, however is still under discussion because of several minor improvements needed and inconsistencies removed. Draft criteria of the level 3 are far from completion and first draft of explanatory notes is available for further discussion by the SDC Subcommittee [7].

Under pressure of higher bodies of IMO the SDC Subcommittee agreed that finalized second generation stability criteria (SGSC), should be presented for acceptance by the MSC by 2019 at the latest. This means, that actually they must be completed at the next session of the SDC Sub-committee. This seems to be unrealistic [8].

\section{APPLICATION OF THE SECOND GENERATION STABILITY CRITERIA TO SAMPLE SHIPS}

Preliminary criteria of the level one and two for all five stability failure modes as drafted in 2013 were verified by several countries against a rather large number of sample ships of different types and the results obtained were submitted to IMO Sub-committee. However, only criteria of level one and two were used for verification as only those were available. Criteria of level three are not yet finalized.

Results of the verification revealed two main problems with application of SGSC. Problem one appears to be inconsistency in application of level 1 and level 2 criteria for almost all stability modes. Inconsistencies occur when standards of vulnerability criteria level one is satisfied without satisfying level two. This is the serious problem discussed by the delegation of the United States, [9] where proposal were made to further consider the criteria and to make attempt to discover causes of these inconsistencies in order to improve standards accordingly.

According to the opinion of the author, this inconsistency could be expected. The method of checking any phenomenon in stages, using subsequently more accurate tools, is logical and well known. But the results would be consistent only if the same tools, but more accurate, were used in subsequent stages. If different tools were used. inconsistencies will occur inevitably. In case of proposed SGSC different tools were used in level one and two

The second problem is more serious. The working group noted the concern of Norway. It was shown that when applying the five vulnerability criteria, about 40 out of 57 ships tested do not meet the level 1 and 2 criteria, hence need to apply either operational restrictions or undertake the expensive and time consuming process of level 3 calculations, that are not yet available. Norway pointed out, that these results are not backed by experience on operating existing ships, nor by any accidents statistics [8]
Tompuri et al from NAPA [10] pointed out correctly that the hull form is the most critical parameter governing two of the five stability scenarios, namely parametric resonance and loss of stability on wave crest. Changing the hull form by adopting more fuller form of the water plane in order to satisfy the standards is unrealistic, because it will affect negatively ship resistance and therefore fuel consumption. Eco-efficiency is the most important parameter governing ship design. It is very unlikely that these kind of very rare stability failure events would be used as determining design factor, instead of eco-efficiency.

\section{PRESCRIPTIVE VERSUS RISK-BASED CRITERIA. GOAL ORIENTED APPROACH}

Traditional regulations were of prescriptive nature. They are formulated in the way where ship dimensions or other characteristic (e.g. metacentric height) must be greater (or smaller) than certain prescribed quantity. Prescriptive regulations could be developed on the basis of experience, statistics, analytical methods, computer simulation, model tests and full-scale trials. Deterministic or probabilistic calculations may be employed when developing the criteria, although, as a rule, deterministic approach is used in most cases.

The main shortcoming of prescriptive regulations is that they are bounding designers and they do not allow introduction of novel design solutions. They are based on experience gained with existing objects and they are not suitable for novel types. Usually they were amended after serious casualties happened. The risk involved with the application of prescriptive regulations is not known.

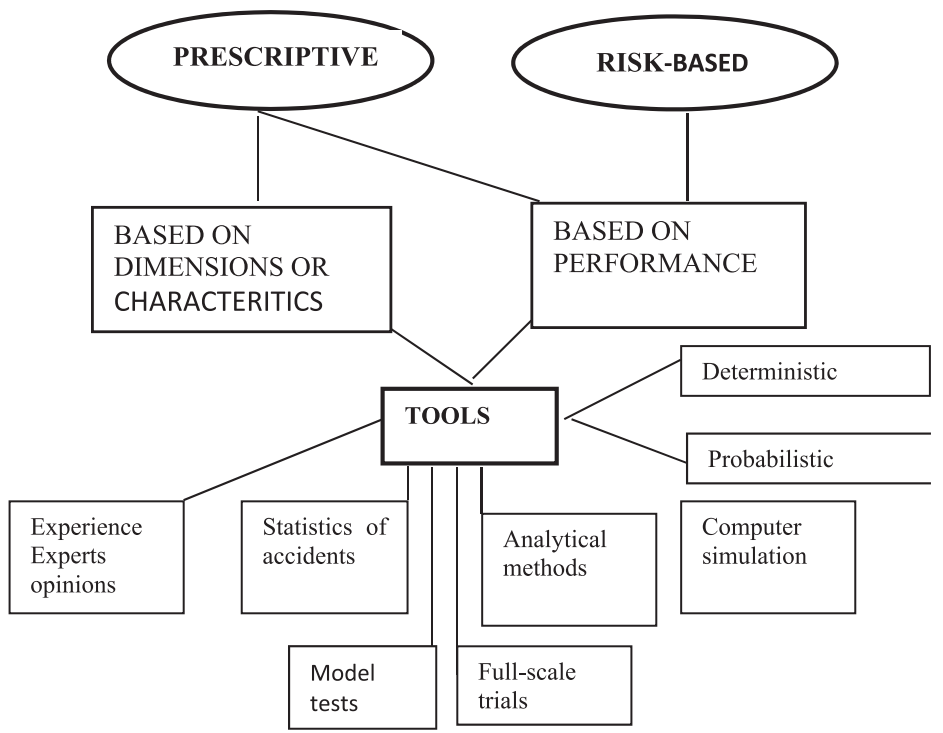

Fig.2. Comparison of risk based and prescriptive standards

At the opposite of the prescriptive regulations, there is riskbased approach. In the risk-based approach, the regulations specify objectives to be reached, which are safe performance of an object. Risk-based approach could be described as a goal-oriented performance based approach utilizing, as a rule, 
probabilistic calculations. However, it is possible to imagine risk-based approach utilizing deterministic calculations as well. The same tools could be used as when developing prescriptive regulations.

The schematic representation of comparison of these two approaches is shown in fig. 2. The advantages of risk-based approach are obvious. They give free hand for the designer to develop new solutions, they actually allow taking optimal decisions from the point of view of economy and safety and the risk to the public and to the environment is assessed and accepted. Risk-based approach includes risk control options either related to design or operation including human factor. Risk based approach is used in situations of high uncertainity.

All existing stability regulations are of the prescriptive nature. At present, however, the need to apply risk-based approach is recognized. The Marine Safety Committee of IMO recommended this approach as Formal Safety Assessment (FSA) [11]. Risk-based approach is widely used in many fields of technology, also in maritime industry [12]. It was used also in the new IMO regulations on damage stability and survivability of ships

The risk-based concept of assuring safety is supplemented by goal-based approach to safety requirements. Goal based approach does not specify the means of achieving safety but sets goals that allow different or alternative ways of achieving safety [13]. Goal-based approach is for some time considered at IMO and appraised by some authors as a best solution to assure safety in very complex situations [14], It was introduced in some areas, albeit not in the systematic manner. Marine Safety Committee of IMO recommended in 2004 at MSCC $78 \mathrm{~s}$ work on goal-based standards in relation to ship construction adopting five-tier systems shown in the table 2 .

Tab.2. Five-tier system for goal-based requirements

\begin{tabular}{|c|l|}
\hline Tier I: & Goals \\
\hline Tier II: & Functional requirements \\
\hline Tier III: & Verification criteria of compliance \\
\hline Tier IV & $\begin{array}{l}\text { Technical procedures and guidelines, classification } \\
\text { rules and industry standards }\end{array}$ \\
\hline Tier V & $\begin{array}{l}\text { Codes of practice and safety and quality systems for } \\
\text { shipbuilding, ship operation, maintenance, training } \\
\text { etc. }\end{array}$ \\
\hline
\end{tabular}

The advantage of goal-oriented approach is that in order to achieve goal which is to make shipping safer, various means have to be used, not only prescriptive regulations. All means that may contribute to safety have to be used as is specified in the table 2. This approach includes risk analysis, which is one of the most important method to achieve compliance.

\section{CRITICAL OBSERVATIONS REGARDING SECOND GENERATION STABILITY CRITERIA}

The adopted methodology of second generation criteria leads to purely prescriptive design standards. Analysis of causes of casualties reveals without doubt that in almost all cases the casualty scenario is very complex and several factors contribute to the end result. Casualties where one single cause may be identified are extremely rare. Usually, apart from design faults, also operational factors, including human factor, play important part. In particular, according to general opinion of ship operators, human factor is responsible for about 90 per cent of all casualties. In order to improve safety and reduce the number of casualties related to stability focus should be concentrated on human factor.

As mentioned the five modes of stability deficiency chosen for consideration are actually selected quite a long time ago, but the SLF Sub-committee decided to abandon the subject and instead include wording, that is still present in the latest edition of the IS Code in the part A (paragraph 1.2) and in Part B (paragraph 5.1). In particular the last one is drawing attention to human factor:

"Compliance with the stability criteria does not ensure immunity against capsizing, regardless of circumstances, or absolve the master from his or her responsibilities. Masters should therefore exercise prudence and good seamanship having regard to the season of the year, weather forecasts and navigational zone and should take appropriate action as to speed and course warranted by the prevailing circumstances."

This is very important statement. Human performance may be affected by several factors, e.g. by education, training, physical and psychical attributes of people at the control, etc. This is separate subject that will not be discussed here. Hazards considered in the present second generation criteria are important. However, with the current approach to drafting standards, no attempt was made to evaluate risk of the considered stability failures on the basis of statistics, expert opinions, analysis of casualties or using other means.

Moreover, physically five modes of stability failure considered are widely different, and they should be considered separately, perhaps using different methods. Trying to consider all of them using the same schematic procedure seems to be wrong, because different physical phenomena require appropriate, perhaps different, methods of analysing and control.

This could be the crucial point. For example casualties resulting from parametric resonance in head or following seas appears to be extremely rare events. Parametric resonance may happen quite often when the wave encounter period is twice the natural period of roll (which is a function of GM). This phenomenon may be easily avoided if period of encounter is slightly changed by changing speed or heading or both of the ship. Moreover hazardous situation may occur only when resulting rolling amplitudes increase and are finally larger than certain accepted value. Therefore if amplitudes resulting 
from parametric resonance are small, there is no danger. In an unpublished paper Wawrzyński and Krata [15] correctly proved, that because of the form of GZ curve, metacentric height at larger angles of inclination quickly changes and parametric resonance disappears.

Extremely large effort to investigate parametric resonance was devoted during recent years and a great number of important papers were published on this subject (e.g. [16, 17]). Also a large number of documents containing studies of the effect of parametric resonance on stability were submitted to IMO. Actually, the main reason of taking parametric resonance into consideration was one casualty of large container ship [18] where due to parametric resonance in head waves serious damage to the container staples leading to loss of several containers and some damage to the ship hull happened.

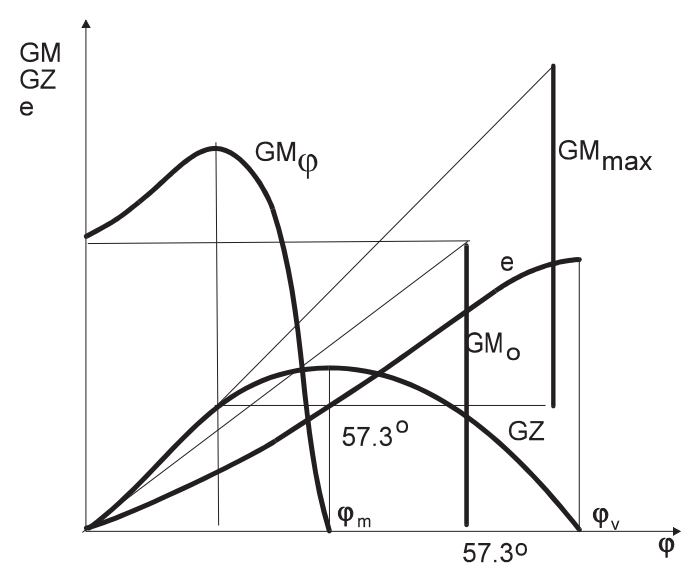

Fig.3. Relation between $G M_{0}$ and $G M_{\varphi}$

However, careful analysis of about three hundreds casualty reports [19] reveals that cases where the casualty may be attributed solely to parametric resonance could not be found and if parametric roll happened, usually was associated with other hazards.

It appears that this approach is charged by some disadvantages and even some countries expressed now the view that the criteria proposed until now are too complicated and in particular at level three they require application of the rather sophisticated computer programmes that are not commercially available [10].

\section{SOME THOUGHTS ON FUTURE APPROACH TO STABILITY}

The present approach to SGSC does not include hazards evaluation. However hazard identification and evaluation of its probability, as already pointed out, constitutes first step in safety assessment. Various means may be used to identify hazards to stability and to evaluate their probability. Important hazards are caused by forces of the sea.

Ship sailing in rough seas is subjected to external forces created by waves, wind, and current. In the paper presented to
STAB conference [20] the author identified numerous hazards to the ship due to action of sea forces apart from changes of GZ curve on wave crest and broaching. All of them should be taken into account. Some of them may happen more often than parametric resonance but somehow they are not included into consideration (see Table 3).

Tab. 3. Some simple capsizing scenarios in waves

\begin{tabular}{|l|l|}
\hline \multicolumn{2}{|c|}{ Scenario } \\
\hline 1 & Pure loss of stability in wave crest \\
\hline 2 & Parametric resonance, following or head seas \\
\hline 3 & Quartering seas \\
\hline 4 & Bow submergence, "green seas" \\
\hline 5 & Rolling in beam sea, resonance, parametric resonance \\
\hline 6 & Beam seas, "three sisters" waves \\
\hline 7 & Beam seas, wind gust, icing, loose goods \\
\hline 8 & Freak waves \\
\hline 9 & Lurching, non-linear singularities \\
\hline 10 & Breaking waves \\
\hline 11 & Water on deck, pseudostatic heel \\
\hline 12 & Broaching to \\
\hline
\end{tabular}

It must be noted, that motions of the ship in sea waves is strongly nonlinear process as well as also irregular wind created waves are strongly non-linear. Because of that it must be expected that certain singularities must appear. So called lurching, i.e. sudden very large heel in comparatively calm sea, that sometimes is reported by ship masters, may be result of this phenomenon that usually is attributed to parametric resonance, where in fact it is caused by singularity of the process. This may be very rare event, but an example of this is shown in fig. 4 , where record of wave height shows a single wave of the height 25 metres, that is 2,5 higher than significant wave height approximately equal to about 10 metres.

Another hazard considered, loss of stability in wave crest, happens more often, however both effects, parametric resonance and loss off stability in wave crest may be easily avoided with proper handling of the ship and not putting the ship in situation when those phenomena may occur (e.g respecting recommendation MSC.1/Circ.1228). The same reasoning is applicable to surf riding and broaching, hazards in fact dangerous for rather fast small ships.

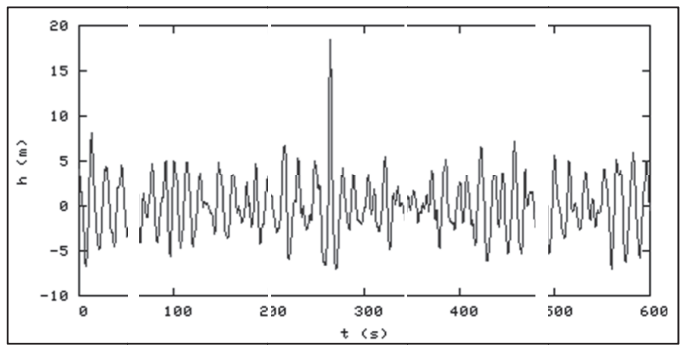

Fig.4. Record of the waves with singularity shown.. [21] 
With broaching criterion the obvious difficulty, as pointed out by Tompuri et al [10], is that the calculation require the calm water resistance as a function of velocity and detailed data on the propulsion. Those data are generally not available in preliminary design and certain approximations must be used. Moreover, stability does not affect the results.

Different situation exists regarding hazard defined as dead ship condition. The present weather criterion, as it appears in the IS Code, in fact covers the situation of the dead ship condition. In general opinion weather criterion is working well for the majority of ships, However some unconventional ships, e.g. ships with large windage area and large $\mathrm{B} / \mathrm{L}$ ratio, as for example large cruise vessels and similar, often have difficulty to meet this criterion. On the other hand experience shows that large passenger ships are reasonably safe.

IMO SLF Subcommittee already took care of this effect developing guidelines for alternative assessment of the weather criterion adopted by resolution MSC.1/Circ.1200. In the view of the author, problem of dead ship condition, that is virtually problem of the weather criterion, could be considered as solved, at least for the time being.

Barnett [22] pointed out, that the safety system or organisation should be considered as a series of barriers against potential failure. Similar concept was proposed by Gower-Jones and van der Graaf as "Tripod method", also including concept of barriers.[23]. These barriers may take different forms including hardware, software, human action etc. Presence of those barriers will prevent casualty Sometimes only the last barrier will hold (a near miss). This idea was tested by Szozda [24] on the example of casualty of ferry boat "Jan Heweliusz", where several barriers were discovered, all of them could hold, but in fact they did not, and the ship capsized.

Improvement of the design characteristics of the ship or even eliminating all possible causes where faulty design is the main cause of casualty may affect only small percentage of casualties. Concentrating main effort on design characteristics of ships is therefore not the most important task.

IMO current work on second generation stability criteria consisting of taking into account some stability failure scenarios identified as important, will certainly increase the level of safety from the stability point of view. However, analysis of stability casualties reveals that chosen stability failure modes are not the most frequent ones. Although current approach to second generation stability criteria includes consideration of some important hazards it does not take into account hazards probability.

It seems, that if the probability of hazard is lower than certain assumed value, such hazard may not be considered further. How to assess hazard probability is another matter. Obviously probability of hazard depend to some extent on ship design, but more on ship operation and human factor. Parametric resonance may be easily avoided by following by the master operational guidance. Within the second generation stability criteria operational guidances are included in the scheme. They may be. developed on the basis of existing resolution MSC.1/Circ.1228. Operational guidelines are proposed however as alternative to direct stability assessment as shown in the table 1 .

\section{CONCLUSIONS}

IMO current work on second generation stability criteria is almost completed, however its application to sample ships revealed certain inconsistencies and deficiencies of the approach creating some concern of interested parties. Finalisation of the criteria and developing corresponding stadards in short time seems to be unrealistic.

In general opinion existing criteria as in the IS Code 2008 are working well for conventional ships. Experience of application of the existing intact stability requirements reveals that stability failures with ships meeting the criteria are extremely rare.

The main weakness of the approach used in developing the second generation stability criteria is lack of the analysis of the risk involved with the chosen stability failures. Analysis of stability casualties reveals that stability failure modes considered in the second generation stability criteria are not the most frequent ones and some of the are extremely rare. The major benefit of the results of second generation stability criteria is increased knowledge of physical phenomena related to motions of a ship in a seaway.

For non-conventional ships the existing requirement of the IS Code 2008 may be inadequate and alternative ways of assuring safety should be used. Applying alternative means is allowed under the provisions of SOLAS Convention. Alternative means may include risk assessment and goal oriented approach.

In the opinion of the author it is now time to apply different, more universal procedures to stability criteria. These are already considered widely, recommended by IMO higher bodies and already used in drafting safety precautions.

\section{REFERENCES}

1. IMO, International Code for Intact Stability, 2008

2. Kobyliński L., Kastner S.: Stability and Safety of Ships. Vol. 1, ELSEVIER 2003

3. IMO: Intact stability. General philosophy for ships of all types. Submitted by Poland, doc STAB XXII/6, 1978

4. IMO: Report to the Maritime Safety Committee. Subcommittee on stability, and load lines and on fishing vessel safety, Doc. SLF 51/17, 2008

5. Peters W., Belenky V., Bassler C., Spyrou K., Umeda N., Bulian G., Altmayer B. (2011). The Society of Naval Architects and Marine Engineers. Annual Meeting Paper.

6. IMO: Second generation stability criteria. Submitted by 
Poland, doc. SLF 54/ 14, Annex1, 2012

7. IMO, Report of the working group, doc SDC 1/5/6, 2013

8. IMO 2017. Finalization of second generation intact stability criteria. Report of the corresponding working group (Part 1), doc. SDC 4/WP.4

9. IMO 2017. Concerns relating to the finalization of the second generation intact stability criteria. Submitted by the United States, doc. SDC 4/5/7

10. Tompuri M., Ruponen, F., Forsa M., Lindroth D, 2016: Application of the second generation intact stability criteria in initial ship design. SNAME Annual Meeting

11. IMO: Interim guidelines for the application of Formal Safety Assessment (FSA) to the IMO rule-making process, doc. MSC/Circ.829; MEPC/Circ.335, 1997.

12. Safedor. Risk-Based Approaches in the Maritime Industry. , Second International Workshop Glasgow, May 2008

13. Hoppe H.: Goal based standards - a new approach to the international regulation of ship construction. IMO News, Issue 1., 2006

14. Papanicolau A. D.: Goalds-Goal based damage stability of passenger ships. SNAME Annual Meeting, 2012

15. Wawrzyński W., Krata P.: Proposal of revision of the practical approach towards IMO Circ. 1228 and the Intact Ship Stability Code application with regard to the naturel period of roll calculation. Unpublished paper presented to Polish IMO Committee, 2017

16. Peters W., Belenky V., Bassler C., Spyrou K., Umeda N., Bulian G., Altmayer B. (2011). The Society of Naval Architects and Marine Engineers. Annual Meeting Paper.

17. Belenky V. L., Weems K.M., Paulling J.R.: Probabilistic analysis of roll parametric resonance in head seas. 8th Stab Conference, Madrid, 2003

18. France, W.N., Levadou, M., Treakle, T W., Paulling, J.R., Michel, R.K., Moore, C.,: An investigation of head sea parametric rolling and its influence on container lashing systems. SNAME Annual meeting, 2001

19. Kobyliński L.: Zestawienie statków uległych awariom LOSA. Unpublished report. Foundation for Safety of Navigation, 2006

20. Kobylinski L.: Capsizing scenarios and hazards identification. 9th International STAB Conference, Madrid. 2003
21. Dysthe K.B., Krogstad H.E., Socquet-Juglard H., Trulsen K.: Freak waves, rogue waves, extreme waves and ocean wave climate. www.math.uio.no, 2007

22. Barnett M., L.: Searching for root causes of maritime casualties. WMU Journal of Maritime Affairs, Vol.4, No. 2, 2005

23. Gower-Jones A.D., van der Graaf G.C.: Experience with Tripod BETA incidents analysis. Society of Petroleum Engineers International Conference, Caracas, 1998

24. Szozda Z.: Application of the TRIPOD method for human factor analysis on the example of $\mathrm{m} / \mathrm{f}$ Jan Heweliusz capsizing. 10th International STAB Conference, St Petersburg, 2009

\section{CONTACT WITH THE AUTHOR}

Lech Kobyliński

e-mail:lechk@portilawa.com

Polish Academy of Sciences

The Committee on Transport of the Polish Academy of Sciences

Palace of Culture and Science, Plac Defilad 1

00-901 Warsaw

Poland 